\section{POLYPEPTIDES OR AMINO-ACIDS}

THE origin of biological macromolecules and life on Earth is, like the possibility of extra-terrestrial life, a subject for speculation and experiment. There is no likelihood of producing protein and nucleic acid selfreplicating systems from simple inorganic molecules in the foreseeable future. This, quite rightly, does not deter everyone from seeing what can be obtained from simple mixtures of the gases that were probably present in the primeval atmosphere.

The primeval atmosphere was almost certainly a reducing environment containing hydrogen, methane, ammonia and hydrogen cyanide, so it seems reasonable to believe that proteins somehow arose from condensation products of these gases and water. When Miller (1955) in his pioneering experiments-repeated many times since-found that mixtures of ammonia, methane and water yield $\alpha$ amino-acids when subjected to high energy radiation or electrical discharge, it was speculated that proteins arose in the primeval seas by polycondensation of $\alpha$ amino-acids. Matthews and Moser, on page 1230 of this issue, question this idea. They suggest that polypeptides and proteins in fact arose directly from the condensation products of hydrogen cyanide, ammonia and other gases and not by the condensation of pre-existent $\alpha$ amino-acids. They have shown that the products from mixtures of ammonia and hydrogen cyanide when dissolved in water yield polypeptides but no free amino-acids. On hydrolysis, this peptide material yields no fewer than fourteen $\alpha$ amino-acids, assuming that the amide precursors of aspartic and glutamic acids were formed. As expected, because the gas mixture used contained no acetylene or hydrogen sulphide, aromatic and sulphur containing aminoacids were not formed.

Matthews and Moser propose that dimerization and subsequent polymerization of the hydrogen cyanide forms polyaminonitrites which then react with water to give the peptide material. They also believe that the free $\alpha$ amino-acids found by other workers were in fact produced by the hydrolysis of peptides. If, as is likely, the primeval atmosphere contained acetylene and hydrogen sulphide, it is perfectly possible that polypeptides containing all twenty $\alpha$ amino-acids were produced in this way and subsequently gave rise to today's proteins. It will be a long time before anybody can hope to know for certain whether polypeptides gave rise to $\alpha$ amino-acids or whether things happened the other way about, but the idea is stimulating.

\section{NEWS GATHERING}

LATER in the year, Nature will begin a new venture in gathering and presenting news about science to the public and the scientists. Under an agreement with the Times (of London), this journal will provide the Times with regular news of important developments in science. This will take the form of a daily column written by the staff of Nature. At the same time, it will be possible for this journal to improve enormously on the news of developments within the profession of science which it at present offers to its readers. Not only will there be more people to do the work, but Nature will have access to the network of international communications at present used to provide the Times with a foreign news service.

Readcrs of both journals will benefit. Nature is particularly glad of an opportunity to help with the dissemination of news about science to the general public, for the excitement and significance of modern science are inadequately appreciated. It is important, however, that an arrangement like this should not compromise the independence of the two journals, which is why it has been agreed that Nature should be in sole charge of the contributions offered to the Times each day and that the service thus provided will supplement and not replace the coverage of science now provided by the Times. It goes without saying that contributors to Nature can be sure that their communications will in future, as in the past, be dealt with in confidence and objectively. If there is any interaction at all between the news service and the function of Nature as a vehicle for original communication, it will probably take the form of a further increase in the speed with which manuscripts are turned into print.

\section{NO LINGUA FRANCA}

ThE resignation last week of the Indian Foreign Minister, Mr M. C. Chagla, has again drawn attention to language problems in India and to the Indian Government's determination to implement immediately the decision to replace English by regional languages as the medium of teaching in Indian universities. It is easy enough to understand the Indian desire to remove what may seem to them to be vestiges of a colonial past, and there is plenty of evidence from elsewhereWales, for example--that language ranks high in national pride. But in India, with no universally spoken or accepted language, the change is impractical and unrealistic. It will inevitably lead to a lowering of the standards of education and to a further isolation of Indian universities which India can ill afford. Until Hindi, now spoken by only about 40 per cent of the population of India, has become a universal language, there are to be no fewer than fifteen accepted regional languages. Will India face the chaos of translating textbooks and journals into all of these ? And will teachers be obliged to lecture in a language in which they lack proficiency? Many hoped that the English language might remain as the most useful legacy of imperial India, and it is ironic that the Indian Government has felt obliged to replace English by obscure regional languages. Will their decision help to ruin Indian unity as well as Indian universities? 